\title{
Research of Innovation Diffusion on Industrial Networks
}

\author{
Yongtai Chen ${ }^{1}$ and Shouwei $\mathbf{L i}^{2}$ \\ ${ }^{1}$ School of Management and Engineering, Nanjing University, Nanjing 210008, China \\ ${ }^{2}$ School of Management, Jiangsu University, Zhenjiang 212013, China \\ Correspondence should be addressed to Shouwei Li; shouweili1996@163.com
}

Received 10 January 2014; Revised 22 June 2014; Accepted 25 June 2014; Published 14 July 2014

Academic Editor: Chuandong Li

Copyright (C) 2014 Y. Chen and S. Li. This is an open access article distributed under the Creative Commons Attribution License, which permits unrestricted use, distribution, and reproduction in any medium, provided the original work is properly cited.

The real value of innovation consists in its diffusion on industrial network. The factors which affect the diffusion of innovation on industrial network are the topology of industrial network and rules of diffusion. Industrial network is a complex network which has scale-free and small-world characters; its structure has some affection on threshold, length of path, enterprise's status, and information share of innovation diffusion. Based on the cost and attitude to risk of technical innovation, we present the "avalanche" diffusing model of technical innovation on industrial network.

\section{Introduction}

Innovation is often expressed as a single event. The appearance of innovation would activate the diffusion of it necessarily, but the diffusion always displays a continuous and slow process. The diffusion of innovation decides the steps of economic development and the rate of productivity finally. The innovation could contribute to society when it is adopted by many adopters. It is obvious that the real value of innovation is not itself but the diffusion of it [1]. So, there is a very important significance to research the diffusion process of innovation.

Under the environment of market economy, all kinds of relationships between enterprises would be generated through the process of their manufacture and management, such as codevelopment, share hold, and transfer of technique. The relationship among some enterprises in industry can form a network which covers the whole industry. Industrial network is constructed by many enterprises and relationships between them. These enterprises consist of many forms, researching institute and government department, which hold their special resource. These nodes in industry network depend on each other because of holding different resources. Some formal or informal reciprocal relationships come into being through their interaction of manufacture and cooperation. Industrial network is a configuring mode of resources between enterprises [2]. Industrial network can play an important role in the development of area economy. It does not only present the platform of interaction for every node in industrial network, but also saves the cost of trade between enterprises, quickens the speed of circulation and studying of information, and then strengthens the competition of enterprises and industry. The structure of industry network would affect the diffusion process of technical innovation.

The new theory of industry area which is represented by Potter strengthens the forming and exterior effect of industrial networks. The essence that industrial networks can enhance the advantage of competition is the alliance of stratagem between enterprises by their cooperation. It is important that the relationship exist between leaguers in industrial networks. The relationships in industrial networks are all kinds of contact which are generated in the process of resources exchanging and transferring between enterprises. These relationships do not only include the "real" relationship, such as industrial chain, service chain, financial chain, and technical chain, but also include the "virtual" relationship, such as knowledge chain and information chain. These "real" and "virtual" relationships do not always overlap each other. The innovative power of industrial networks is represented by the complex character of inner associating mode and interaction between enterprises extremely.

How would the structure of industry network be like? How does it affect the diffusion process of technical innovation? If there is a technical innovation which takes place in 
a node (enterprise), how fast does the technical innovation diffuse in the industry network? What scale does it diffuse? These problems are very interesting and should be focused on by researchers and enterprisers. If we know some laws of innovation diffusion, the power of technical innovation should be amplified to generate more competitive ability. So, the diffusion of innovation on industrial networks will be researched in the paper. A whole diffusing process on network should at least include two aspects: establishment of diffusing rules and choice of network topology structure. The network topology decides the path and mode of innovation diffusion; the rules of diffusion are always determined by the cost and tendency of enterprise's innovation. In Section 2, we analyze the structure of industry network and its affection on innovation diffusion. In Section 3, we present the avalanche model of innovation diffusion on industry network and give more detailed analysis about the distribution after the diffusion process. At last, some conclusions are summarized in the paper.

\section{Affection of Industrial Networks on Innovation Diffusion}

2.1. Diffusing Mode of Innovation. The system of region innovation always includes four kinds of innovation: institutional innovation, innovation of management, innovation of service, and technical innovation. Because the institution, management, and service cannot be copied directly, the studier must understand and grasp the idea behind them profoundly. The things that are diffused by the former three innovations are no-coded knowledge mostly, so the institutional, administrant, and service innovations are called by a joint name, knowledge innovation. Because the technical innovations are always adhering to product, the technical innovation can be divided into product innovation and craft innovation.

Industrial network has two characters: one is the technical character which is based on industrial chain; another is social character which is based on value chain at the same time; interaction between enterprises is frequent; the industrial network is propitious to the diffusion of innovation specially, but the mode of diffusion is different between knowledge innovation and technical innovation. Technical innovation diffuses through the "real" relationship of industrial network, but knowledge innovation diffuses through the "virtual" relationship of industrial network. Because the "real" relationship can be investigated and analyzed easily, the affection of industrial network topology on innovation diffusion would be analyzed in the following by the "real" relationship between enterprises. So, the structure of industry network is analyzed in the following part.

2.2. Complex Topology of Industrial Network. If we analyze the affection of industrial network topology on innovation diffusion, the topology of industrial network should be cognized firstly. The industrial network also is a kind of network. The research of network could be divided into three phases approximately: regular network, random network, and complex network.
Complex networks are the massive networks which have complex topology structure and dynamic behavior [3]; complex networks are the graphs which are constructed by many interlinks among a mass of nodes. The main characters $[4,5]$ of complex network include three aspects: distribution of node degree, average shortest length, and clustering coefficient. If the probability distribution $p(k)$ of node degree $k$ in a network follows power-law distribution, $p(k) \sim k^{-r}, 2<$ $r \leq 3$, the network would be called scale-free network. The networks which have smaller average shortest length and larger clustering coefficient are called small-world network. The scale-free network and small-world network are called by a joint name, complex network. Complex network is a kind of network which is between regular and random network; it is researched widely in recent years because of the veracity depicting real world.

We investigate the relationships between integrate circuit (IC) enterprises in the Yangtze River delta area in china. The relationships include cooperation, strategy alliance, investment, and technical trading. Based on the "real" relationship between enterprises, the industrial network of IC industry in Yangtze River delta area is presented as follows (Figure 1 is drawn by using Ucinet software). There are almost 500 institutes and more than 1200 ties in the industry network.

Applying the statistical analysis method of complex network $[4,5]$, we compute the distribution of node degree and clustering coefficient of the IC industrial network by using Ucinet software. Then the results are showed as follows (Figures 2 and 3).

In order to judge the small-world character of it, we also compute some parameters of the IC industrial network (Table 1). It is noticeable that the ER random network is generated according to the size and density of IC industrial network.

From Figure 1, we can make out that the distribution of node's degree in the IC industrial network follows power-law distribution, $p(k) \sim k^{-r}, r=2.81$; from Figure 2 and Table 1 , we can make out that the IC industrial network has larger clustering coefficient and smaller average shortest length.

Following the above analysis, we can conclude that industrial network is not only a scale-free network, but also a smallworld network. It has the three complex characters: smallworld, scale-free, and clustering, which has the affection of different degree and mode on innovation diffusion in industrial network.

\subsection{Affections of Industrial Network Complex Topology on} Innovation Diffusion. The researches of diffusing threshold on network are mainly based on the famous epidemic models SIS and SIR, but these conclusions are also the same with innovation diffusion on industrial network. The diffusing threshold is not small value in regular network; the diffusing threshold of small-world network is smaller than that of regular network clearly. Under the same intension of diffusion, the spreading size of diffusion in small-world network is larger than that in regular network distinctly [6]. The diffusing behavior is only different on quantity from regular network to small-world network, but the diffusing behavior on scalefree network puts up some characters far from the former two 


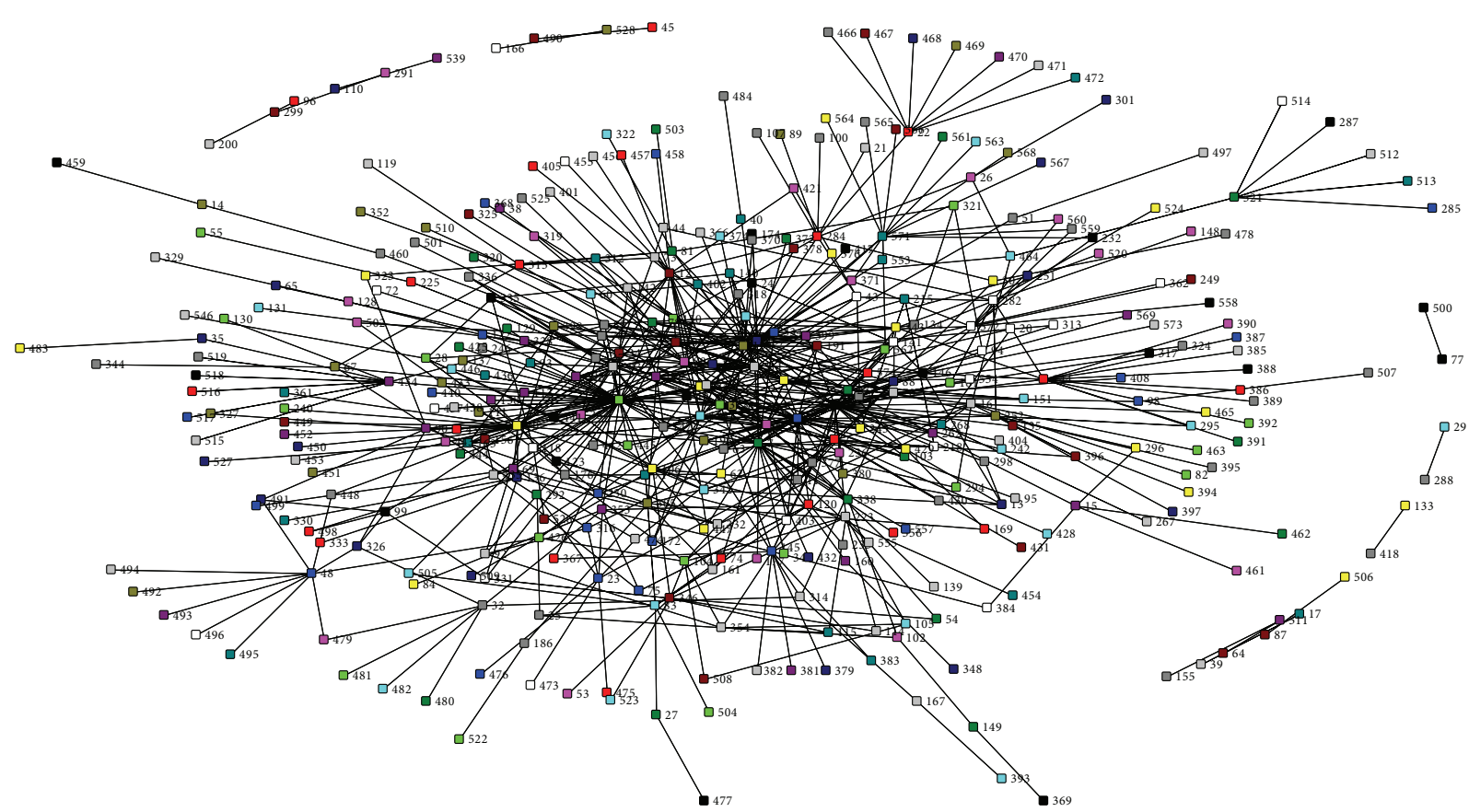

FIGURE 1: The industrial network of IC industry in Yangtze River delta area.

TABLE 1: Comparison between IC industrial network and random ER network.

\begin{tabular}{lcccc}
\hline Type of network & Average degree of network & Max degree of node & $\begin{array}{c}\text { Average shortest length of } \\
\text { network }\end{array}$ & $\begin{array}{c}\text { Average clustering } \\
\text { coefficient }\end{array}$ \\
\hline IC industrial network & 3.503 & 53 & 3.554 & 0.046 \\
ER random network & 3.472 & 10 & 4.261 & 0.016 \\
\hline
\end{tabular}

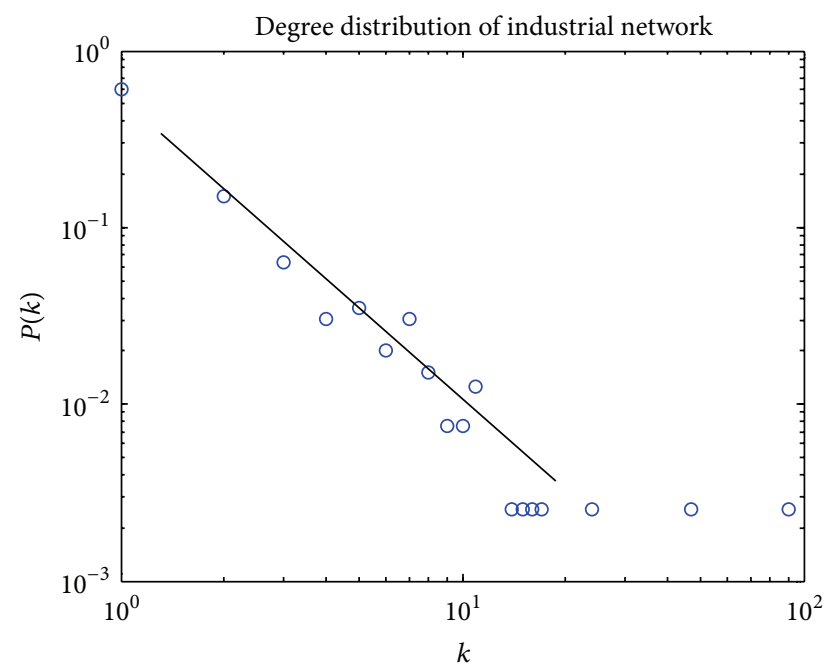

FIGURE 2: The distribution of node's degree of the industry network (double logarithmic coordinate).

networks. The diffusing threshold is negative or close to zero on scale-free network [7]. From these above analyses, we can know that innovation always exists and constantly diffuses and the diffusion would spread to the whole industry.

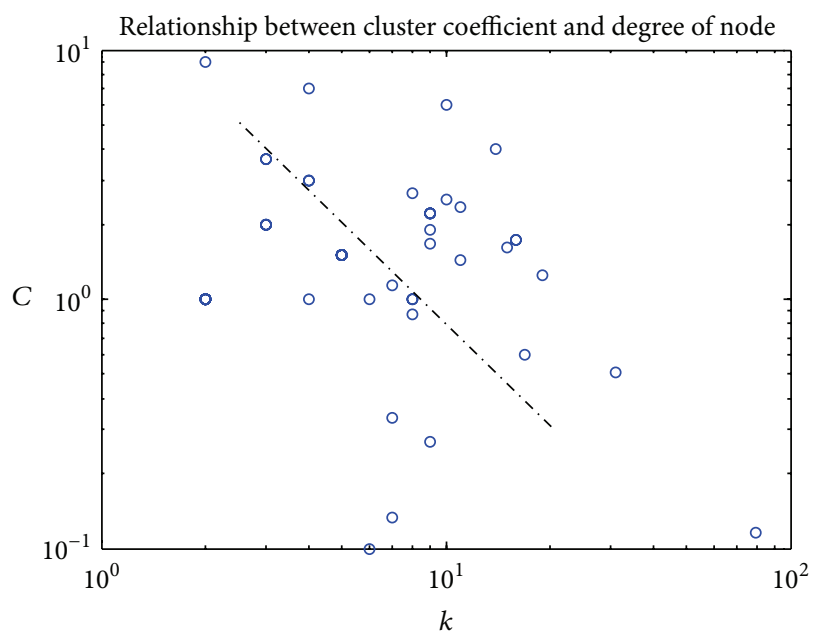

FIGURE 3: The relationship between clustering coefficient and node's degree (double logarithmic coordinate).

From Figures 1 and 2, we can see that the distribution of relationship links in industry network is asymmetry very much. There are a few "Hub" enterprises which have larger links and many enterprises which have a few links. The 
TABLE 2: Affections of industrial network topology on innovation diffusion.

\begin{tabular}{ll}
\hline Type & \multicolumn{1}{c}{ Content } \\
\hline $\begin{array}{l}\text { Diffusing mode } \\
\text { Diffusing }\end{array}$ & Technical innovation spreads on "real" relationship \\
threshold & Industrial network is a scale-free network; innovation can diffuse easily on it, and the diffusing threshold is zero \\
$\begin{array}{l}\text { Diffusing path } \\
\text { Sharing }\end{array}$ & Industrial network is a small-world network; the path of innovation diffusion is shorter \\
innovation & The clustering coefficient of industrial network is very larger; the shared degree of innovation is higher \\
$\begin{array}{l}\text { Innovation } \\
\text { affection }\end{array}$ & $\begin{array}{l}\text { The distribution of node's degree in industrial network; the affection of enterprise innovation on industrial network is } \\
\text { different extremely }\end{array}$ \\
\hline
\end{tabular}

innovation of those "Hub" enterprises will bring greater affection to industrial network than others.

From Figure 3, we can see that the clustering coefficient of each enterprise is different, and the local clustering coefficient $C(k)$ depends on the degree $k$ of enterprise strongly. The degrees of innovation shared between some associated enterprises are different very much. We can know that some enterprises have different status and role in innovation share through the clustering coefficient of them in industrial network.

The new knowledge and new technique are not monopolized by other enterprises immediately. They always diffuse through network, so the average shortest path of industrial network may measure the average shortest length of innovation passing during diffusion. In the IC industrial network of Yangtze River delta area, diffusion of innovation would spread to the whole industry through $2 \sim 3$ enterprises. The small-world character of IC industrial network shows that the diffusion of innovation on industrial network is a quick diffusing process.

Based on the former analyses, we give some conclusions showed by Table 2 .

\section{Rules of Innovation Diffusion and the "Avalanche" Model of Technical Innovation}

Because the variability and chanciness of "virtual" relationships between enterprises is larger, the measurement of knowledge innovation diffusion is very difficult. Knowledge innovations are almost noncoded information, which always diffuse through overflow of knowledge [8]. The "real" relationships between enterprises are stable comparatively, which bring convenience for measurement of technical innovation diffusion. We mainly consider the diffusion of technical innovation on industrial network in the following part.

The enterprise decides whether it upgrades its technical level according to local information generally; that is, the enterprise makes the decision of upgrading technique level based on the technical level of some enterprises which link to it [9].

In order to understand the complex dynamic of technical upgrade in the diffusion process of technical innovation, we should consider how to simulate some local interaction affecting diffusion through industrial network. Most of the times, these "waves" of diffusion come in terms of intermittent bursts separating relatively long periods of quiescence; in other words, the system exhibits "punctuated equilibrium" behavior. Certainly some technologies, like cellular phones or VCRs, seem to lurk in the background for years and then suddenly explode into mass use [10].

There are two main mechanisms involved in the diffusion of innovations in industrial network that any mathematical model should take into account. On the one hand, there is a pressure for adopting a new product or technology coming from marketing campaigns and mass media. These external processes are essentially independent of the industrial network structure and one can view their effects as a random independent process on the enterprises. On the other hand, there is the influence of the surrounding enterprises which link to it in industrial network. Once an enterprise decides to adopt a new technology, those who are in contact with it can evaluate the new payoff and risk the enterprise has got from acquiring the new technology and compare it with their current benefits. By balancing the payoff increment with the associated upgrading cost, they may decide to adopt, or not, the new technology. In this way, the local flux of information plays a key role in diffusing new techniques. It is important to notice that we are not considering any compatibility constraint among the enterprises.

In this article we propose a simple model of diffusion of technological innovations with costs and attitude (related to risk). At the same time, we will give the theoretic analyses of distribution of innovation diffusion.

3.1. Model of Technical Diffusion on Industrial Network. Each enterprise $i$ is characterized by the real variable $a_{i}$. This variable stands for their technological level; that is, the higher the $a_{i}$ is, the more advanced (technologically speaking) it is. We will assume that the payoff that an enterprise receives from possessing a certain technological level is simply proportional to it. The model is then simulated as follows.

(i) At each time step, a randomly selected enterprise $a_{i}$ updates its technological level

$$
a_{i} \longrightarrow a_{i}+\Delta_{i}
$$

where $\Delta_{i}$ is a random variable exponentially distributed with mean $1 / \beta$; that is, $p(\Delta)=\beta e^{-\beta \Delta}$. This driving process accounts for the external pressure that may lead to a spontaneous new technology adoption by any of the population enterprises.

This step means that the technical innovation takes place on node $i$ at some time in industry network; then the technical 
level becomes higher than in the past. The difference $\Delta_{i}$ follows exponential distribution with parameter $1 / \beta$, which indicates the time interval of independent technical innovation. Here, Beta denotes the press of technical innovation from actual situation. The larger the Beta is, the larger the press is and the shorter the time interval of independent technical innovation is.

(ii) All enterprises $j \in \Gamma(i)(\Gamma(i)$ being the set of neighbors of enterprise $i$ ) decide whether they also want to upgrade or not, according to the following rule:

$$
a_{i}-a_{j} \geq \frac{C}{p} \Longrightarrow a_{j} \longrightarrow a_{i}
$$

where $C$ (cost) is a constant parameter that stands for the price an enterprise must pay in order to upgrade his technology as well as its personal "resistance" to change. $p$ is a random variable which is defined on $[0,1]$, and $p$ is used to denote the attitude of enterprise to upgrade its technology level. So $p$ is called enterprise attitude of technical innovation. $p=0$ denotes that the enterprise would not like to upgrade its technical level. $p=1$ denotes that the enterprise can upgrade its technical level instantly. $0<p<1$ denotes the degree of attitude to upgrade.

This step means that the technical innovation diffuses from node $i$ to node $j$ under the condition of cost and probability. If the diffusion happened, the technical level of node $j$ should become large. The larger the cost is, the more difficult the diffusion is. The larger the probability is, the less difficult the diffusion is.

(iii) If any $a_{j}$ has decided to also upgrade its level, we let their neighbors also choose whether to upgrade or not. This procedure is repeated until no one else wants to upgrade, concluding $a$ technological avalanche. Whenever an enterprise $a_{i}$ decides to upgrade, their neighbors become aware of the new technology and balance the profit they may obtain in case of also adopting it $\left(a_{i}-a_{j}\right)$ with its cost $C / p$. It may well happen that if the technological innovation spontaneously adopted by the seed of the avalanche is high enough compared with the cost, the avalanche may end up spanning a large portion of the population.

This step means that the technical innovation diffuses from node $j$ to its neighbors. Then, the process is repeated on industry network, which is just same as an avalanche ensued in the whole network.

3.2. Distribution of Technical Diffusion. Assume that there are $n$ nodes and $N(n)$ links in industrial network. From the former demonstration, we can see that industrial network has scale-free and small-world characters. After the enterprise has a technical innovation, its technical level is upgraded. Because there are many links (relationships) between enterprises in industrial network, the technical innovations should spread to its neighbor enterprises.

3.2.1. Probability of Technical Upgrading for Enterprise. Neighbor enterprises would choose whether to upgrade or not according to the affection of innovation diffusion. From formula (1), if $a_{i}-a_{j}=\Delta a \geq C / p$, the enterprise would adopt the new technology and upgrade its technical level. So the probability $p_{1}$ of technical upgrading for an enterprise is as follows:

$$
p_{1}=P\left(\Delta a \geq \frac{C}{p}\right)=1-P\left(\Delta a<\frac{C}{p}\right) .
$$

Because $\Delta a$ follows exponential distribution $e(\beta)$ with parameter $\beta$, that is, $f(x)=\beta e^{-\beta x}$, then $P(x)=1-e^{-\beta x}$. Therefore we have

$$
p_{1}=1-P\left(\Delta a<\frac{C}{p}\right)=e^{-\beta C / p} .
$$

The technical upgrading of enterprise could improve the diffusion of innovation in industry network. The higher the probability of technical upgrading is, the larger and faster the diffusion of innovation is. We can find that the probability of technical upgrading follows exponential distribution with negative index from formula (4). If the cost $C$ increases, the probability of technical upgrading would decrease, so the size and speed of innovation diffusion are smaller and slower, respectively.

\subsubsection{Diffusing Tree of Technical Innovation}

Definition 1. A graph is called $a$ tree of order (size) $k$ if it has $k$ vertices and is connected and if none of its subgraphs is a cycle.

A tree of order $k$ has evidently $k-1$ edges.

From formula (1), we can see that after technical innovation diffuses, all the enterprises which upgrade their technical level from innovation diffusion reach the same technical level lastly. There is no diffusion between the enterprises which have upgraded their technical level, sequentially a tree should be formed during the diffusion of technical innovation, called diffusing tree.

Apparently, a tree of order $k$ is a diffusing tree if and only if the $k$ nodes all upgrade their technical level. So the probability of a tree being a diffusing tree which has $k$ nodes is as follows:

$$
p_{2}=\left(p_{1}\right)^{k}=\exp \left(-\frac{\beta C k}{p}\right) .
$$

From formula (5) of $p_{2}$, we can find that the probability of diffusing tree follows exponential distribution with negative index. The probability of diffusing tree decreases if the size of diffusing tree $(k)$ increases.

After the new technology has diffused, we should consider the diffusion size of technical innovation; that is, how many nodes (enterprises) upgrade their technical level during innovation diffusion. In the other words, we should consider the probability of emergence of diffusing tree of $k$ order during innovation diffusion in industrial network.

In industrial network, we have the following. 
Theorem 2. The distribution of diffusing tree of $k$ order in industrial network follows Poisson Distribution $P(\lambda)$ with parameter $\lambda$, where

$$
\begin{gathered}
\lambda=\lambda_{1} p_{1}, \\
p_{1}=\exp \left(-\frac{\beta C}{p}\right), \\
\lambda_{1}=\frac{(2 \sigma)^{k-1} k^{k-2}}{k !}, \\
\lim _{n \rightarrow+\infty} \frac{N(n)}{n^{(k-2) /(k-1)}}=\sigma .
\end{gathered}
$$
follows.

In order to prove the theorem, we need the lemma as

Lemma 3. If $\lim _{n \rightarrow+\infty}\left(N(n) / n^{(k-2) /(k-1)}\right)=\sigma>0$ and $\tau_{k}$ denotes the number of isolated trees of order $k$ in network $\Gamma_{n, N}$, then

$$
\lim _{n \rightarrow+\infty} P_{n, N}\left(\tau_{k}=j\right)=\frac{\lambda_{1}^{j} e^{-\lambda_{1}}}{j !}, \quad j=0,1,2, \ldots,
$$

where

$$
\lambda_{1}=\frac{(2 \sigma)^{k-1} k^{k-2}}{k !} \text {. }
$$

The Proof of Lemma 3 can be found in literature [11].

Proof of Theorem 2. From the topology structure of industrial network, it can be obtained that industrial network satisfies the condition $\lim _{n \rightarrow+\infty}\left(N(n) / n^{(k-2) /(k-1)}\right)=\sigma>0$.

Assume that random variable $X$ denotes the number of diffusing trees. According to Lemma 3, the probability $P(X=m)$ of emergence of $m$ trees of $k$ order satisfies $P(K=$ $m)=\left(\lambda_{1}^{m} / m !\right) e^{-\lambda_{1}}$ in industrial network. The diffusing tree of $k$ order must be generated from all trees of $k$ order in industrial network. That is, the $m$ diffusing trees of $k$ order can be generated for $m, m+1, \ldots, m+n, \ldots$ trees of $k$ order. Then we can obtain the following:

$$
\begin{aligned}
P(X=m) & =\sum_{n=0}^{\infty} P(X=m+n) C_{m+n}^{m} p_{1}^{m}\left(1-p_{1}\right)^{n} \\
& =\sum_{n=0}^{\infty} \frac{\lambda_{1}^{m+n} e^{-\lambda_{1}}}{(m+n) !} \frac{(m+n) !}{m ! n !} p_{1}^{m}\left(1-p_{1}\right)^{n} \\
& =\frac{\lambda_{1}^{m}}{m !} e^{-\lambda_{1}} p_{1}^{m} \sum_{n=0}^{\infty} \frac{\left(\left(1-p_{1}\right) \lambda_{1}\right)^{n}}{n !} \\
& =\frac{\lambda_{1}^{m}}{m !} e^{-\lambda_{1}} p_{1}^{m} \cdot e^{\left(1-p_{1}\right) \lambda_{1}} \\
& =\frac{\left(\lambda_{1} p_{1}\right)^{m}}{m !} e^{-\lambda_{1} p_{1}} .
\end{aligned}
$$

From Theorem 2, we can judge the size of innovation diffusion when the process of innovation diffusion is completed in industry network. The number of diffusing tree with $k$-nodes follows Poisson distribution, which its mean value and variance equal the parameter $\lambda$. If $\lambda$ is very large, the distribution of diffusing tree of $k$-nodes would approach normal distribution, which consists with the actual situation approximately.

\section{Conclusions}

Industrial network can be formed by some interacting relationship between enterprises in area industry. It has an important affection on the diffusion of innovation.

From the empirical data of IC industry, we construct the industry network. And then we find that the industry network has three characters: scale-free, small-world, and clustering, which have an important affection on the diffusion of technical innovation on industry network.

Because industrial network is a scale-free network, it makes the diffusion of innovation on industrial network very easily, and each enterprise has different affection on the whole industry. Because industrial network is a small-world network, the average path length of innovation diffusion is shorter when it spreads to whole industry. Because the clustering coefficient of industrial network is larger, the sharing degree of innovation is higher.

Knowledge innovations are always noncoded information, which spread by overflow of knowledge, so knowledge innovations diffuse mainly on the "virtual" relationship of industrial network. Technical innovations always adhere to product, which spread by the value chain of product, so technical innovations diffuse mainly on the "real" relationship of industrial network.

A technical innovation of an enterprise can upgrade itself and diffuse to some neighbor enterprises. The neighbor enterprises decide whether to upgrade their technical level or not by analyzing local information (the cost and risk of technical innovation). The process is repeated constantly on industrial network, so an "avalanche" of technical innovation is formed. In order to trigger the "avalanche" of technical innovation, we should reduce the cost of technical innovation and recognize the risk of technical innovation accurately.

The avalanche model of technical innovation diffusion on industry network could extend our ability to management innovation and its diffusion in an industry. One the one hand, we can forecast the size and speed of a technical innovation diffusion after it happens at some time. On the other hand, from the situation of diffusing tree, we can judge the cost and probability of technical innovation diffusion. So, we can decrease the cost and increase the probability to speed up the rate of diffusion and enlarge the size of technical innovation affection.

\section{Conflict of Interests}

The authors declare that there is no conflict of interests regarding the publication of this paper.

\section{Acknowledgments}

This research was supported by the Major project of National Natural Science Foundation of China under Grant no. 
71390521, the National Natural Science Foundation of China under Grant nos. 71171099, 71301070, the National Social Foundation of China under Grant no. 11BJL074, the Humanity and Social Science Foundation of Ministry of Education of China under Grant no. 12YJCZH020, and the Colleges and Universities in Jiangsu Province Plans to Graduate Research and Innovation Projects under Grant no. CXLX13_057.

\section{References}

[1] Y. Q. Mo, T. Z. Wu, and C. J. Wu, "An innovation diffusion study based on social networks," Soft Science, vol. 18, no. 3, pp. 4-6, 2004 (Chinese).

[2] Y. Z. Gai and G. J. Sui, "A model of industrial network formation based on contraction theory: the viewpoint of overall cost," Modern Economic Science, vol. 26, no. 5, pp. 56-59, 2004 (Chinese).

[3] J. Ma, F. C. Tang, J. Guo, and Y. M. Xi, "The application of complex networks theory in organization networks study," Studies in Science of Science, vol. 23, no. 2, pp. 173-178, 2005.

[4] M. E. J. Newman, "The structure and function of complex networks," SIAM Review, vol. 45, no. 2, pp. 167-256, 2003.

[5] R. Albert and A. Barabási, "Statistical mechanics of complex networks," Reviews of Modern Physics, vol. 74, no. 1, pp. 47-97, 2002.

[6] C. Moore and M. E. J. Newman, "Epidemics and percolation in small-world networks," Physical Review E-Statistical Physics, Plasmas, Fluids, and Related Interdisciplinary Topics, vol. 61, no. 5B, pp. 5678-5682, 2000.

[7] R. Pastor-Satorras and A. Vespignani, "Epidemic spreading in scale-free networks," Physical Review Letters, vol. 86, no. 14, pp. 3200-3203, 2001.

[8] J. Wei, "SMEs. Cluster innovation: network effects and knowledge spillovers," Science Research Management, vol. 24, no. 4, pp. 54-60, 2003 (Chinese).

[9] X. Guardiola, A. Díaz-Guilera, C. J. Pérez, A. Arenas, and M. Llas, "Modeling diffusion of innovations in a social network," Physical Review E, vol. 66, no. 2, Article ID 026121, 2002.

[10] P. R. Krugman, The Self-Organizing Economy, Blackwell, Malden, Mass, USA, 1996.

[11] P. Erdös and A. Rényi, "On the evolution of random graphs," Publications of the Mathematical Institute of the Hungarian Academy of Sciences, vol. 5, pp. 17-61, 1960. 


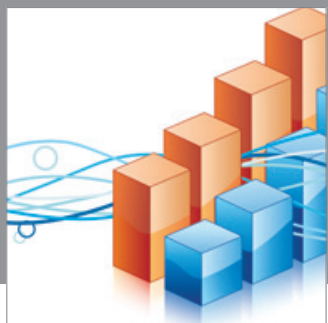

Advances in

Operations Research

mansans

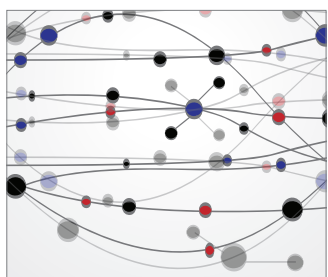

The Scientific World Journal
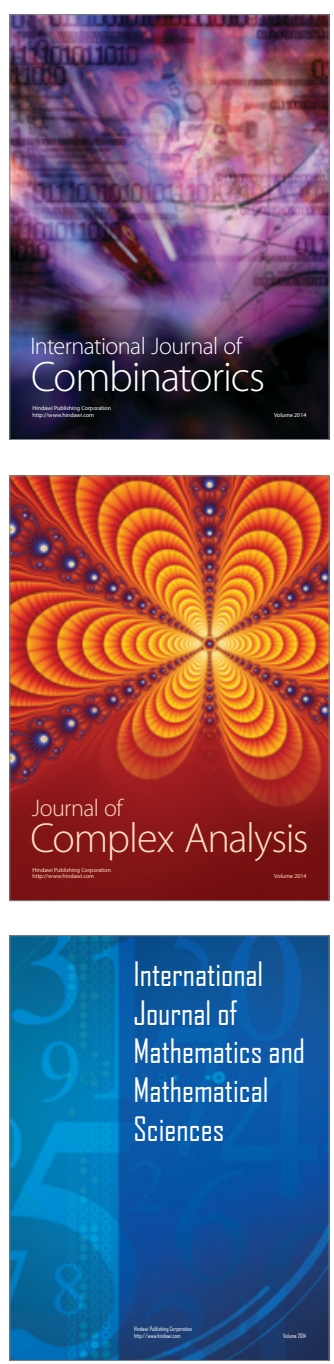
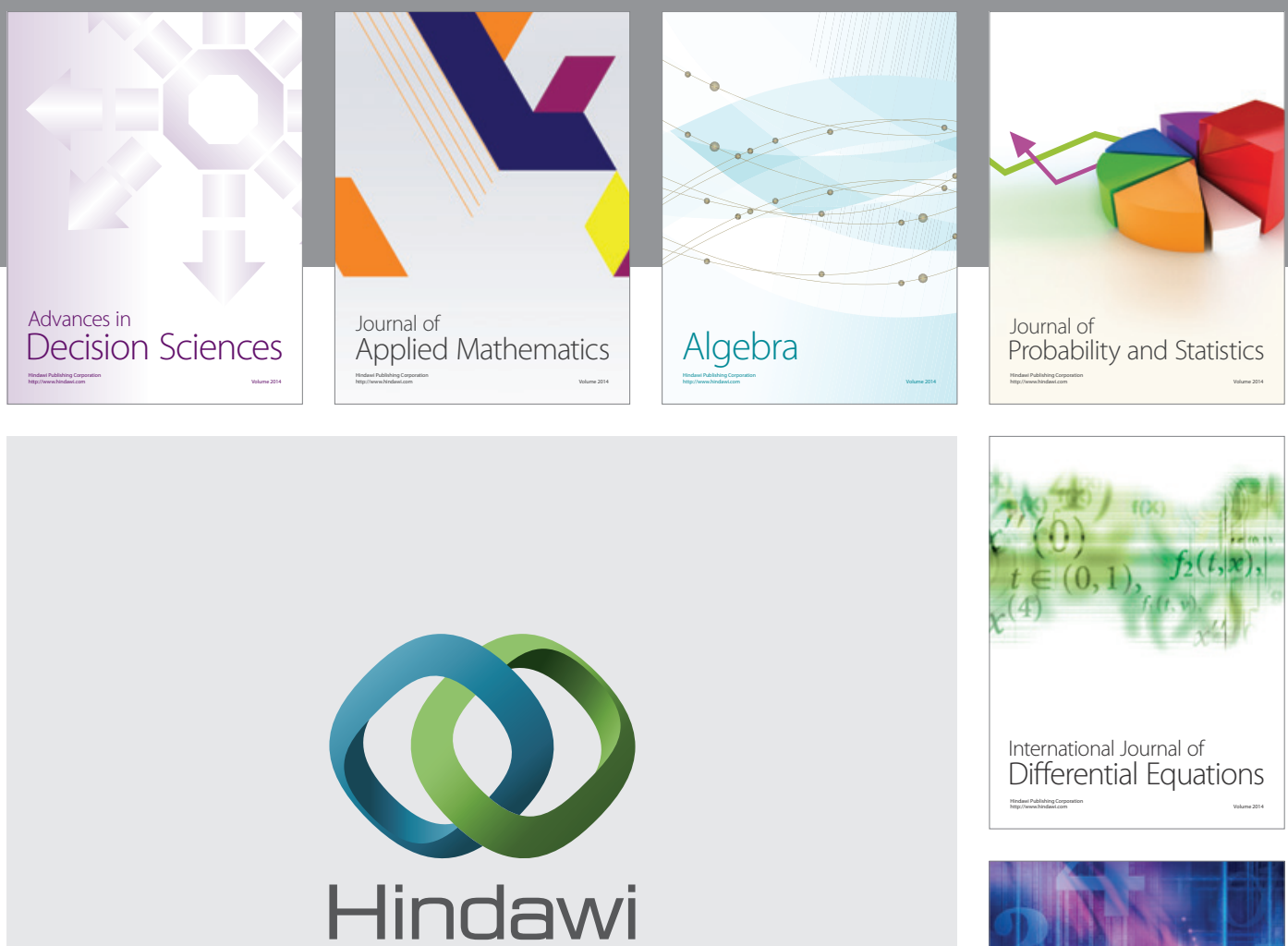

Submit your manuscripts at http://www.hindawi.com
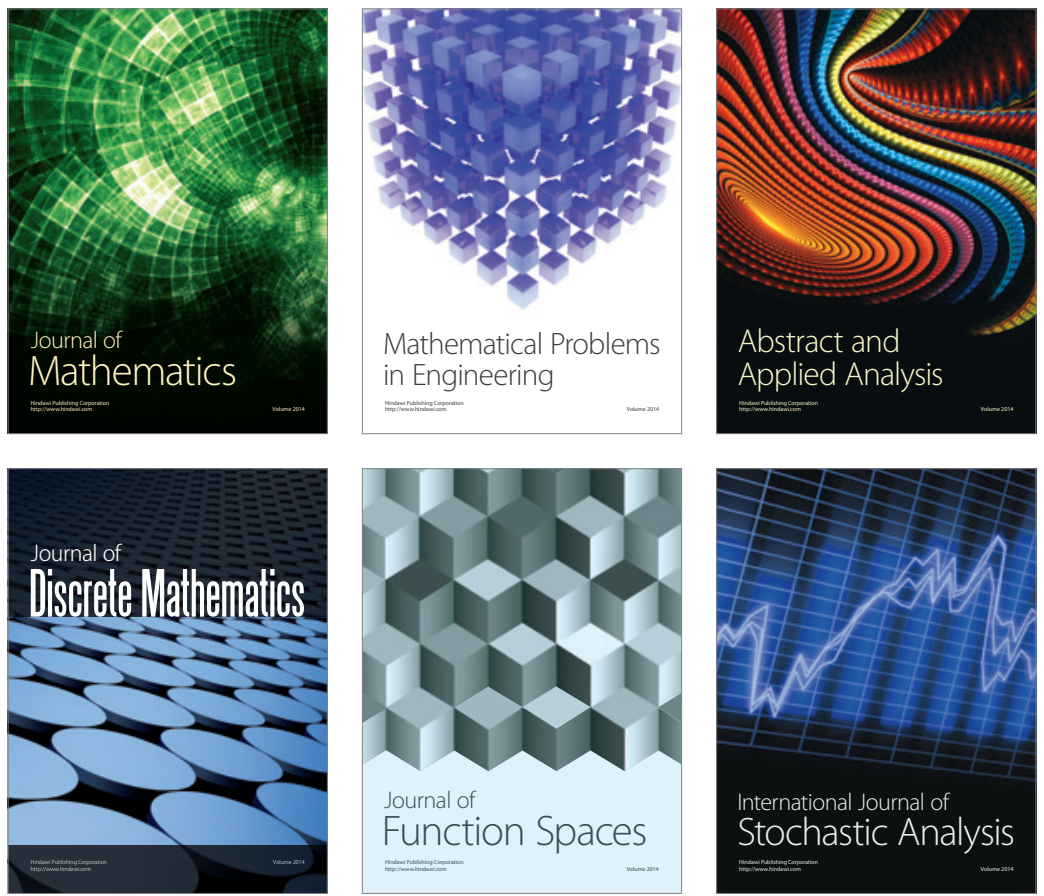

Journal of

Function Spaces

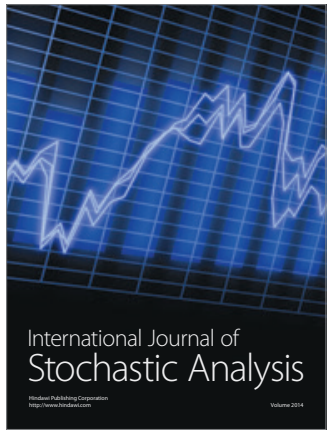

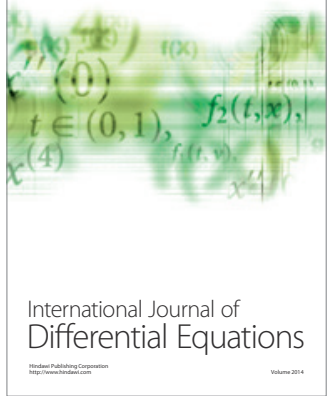
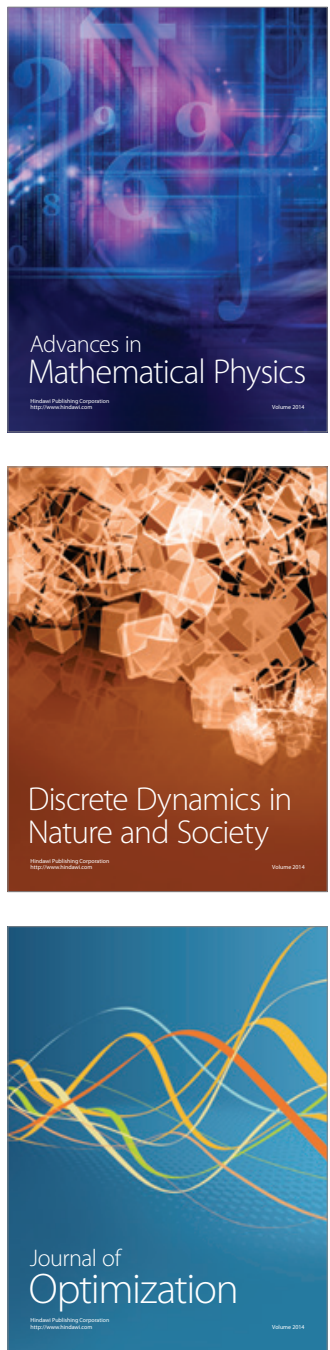